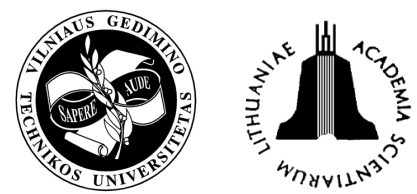

\title{
AUTOMOBILE TRANSPORT SYSTEM ANALYSIS AND RANKING IN LITHUANIAN ADMINISTRATIVE REGIONS
}

\author{
Marius Jakimavičius ${ }^{1}$, Marija Burinskienè $\dot{e}^{2}$ \\ Dept of Urban Engineering, Vilnius Gediminas Technical University \\ Saulètekio al. 11, LT-10223 Vilnius, Lithuania \\ E-mails: ${ }^{1}$ Mjakimavicius@hnit-baltic.lt, ${ }^{2}$ marbur@ap.vgtu.lt \\ Received 6 February 2007; accepted 2 May 2007
}

\begin{abstract}
Identifying accessibility is a standard issue of transport analysis, which can be of interest to many socioeconomic applications. In this paper we propose and discuss the accessibility-based Lithuanian automobile transport system analysis and GIS (geographical information systems) calculation method for searching a potential territory under different conditions. In our analysis the main parameter is time-based accessibility from the centres of Lithuanian administrative regions to all the territory. According to accessibility and regional statistics, i.e. road network density in regions, density of local roads in regions, length of roads per 1000 inhabitants in administrative regions, length of local roads per 1000 rural inhabitants in administrative regions, GIS application computes the ratings for administrative regions. The first stage of GIS decision support system is based on two calculation methods: Topsis (Technique for Order Preference by Similarity to Ideal Solution) and SAW (Simple Additive Weighting). The second stage of GIS application is used for planning accessibility in the Lithuanian administrative regions. Major input into GIS data for this application is the road ant street network. Minor data is as follows: a layer of buildings, engineering utilities and landscape, hydrology, objects of cultural heritage. The application user can also enter different technical parameters: driving time from the centre, possible distance from major road, distance from specific utility, etc. Percentage of territorial distribution for the accessibility in half an hour from the administrative centre was used as a criterion for the calculation of municipalities ranking.
\end{abstract}

Keywords: accessibility, GIS, automobile transport system, road network, road network density.

\section{Introduction}

Accessibility is considered, by planners and other technicians, as a key variable for territorial development and planning. The concept of accessibility incorporates not only the transport link between origin and destination and the ability for traveling by the target group, but also characteristics of the destination and the objective of the trip. However, accessibility can be measured in several different ways, such as composite measures, comparative measures, and the time-space approach; see also [1].

The accessibility concept can be applied to many spatial problems; e.g. service centre location, hospitalsitting, school closure and many others. Analysis based on the concept of accessibility is therefore ideally suited to be integrated into geographical information systems (GIS). This paper expands the work in modeling accessibility fields taken by Donnay and Ledent [2] for the urban region of Liège (Belgium) and Julião [3] for Tagus Valley Region (Portugal), as well as one- stage model for Slovene municipalities [4]. In this paper, travel time (by car) and territorial distribution into the Lithuanian administrative regions have been modeled using the road network and GIS approach. Accessibility from the centre of the administrative region was taken as the main factor for the automobile transport system analysis in the Lithuanian administrative regions. The other factors, such as road network density in regions, density of local roads in regions, length of roads per 1000 inhabitants in administrative regions, length of local roads per 1000 rural inhabitants in administrative regions, have also been included into the evaluation. Georeferenced data about the road network, territorial accessibility from the administrative centres and statistical data, characterizing the structure of the road network, were used as the input data for ranking the automobile transport system according to the administrative regions. The ranking could be used for planning funds, allocated to road infrastructure, according to the administrative regions. 


\section{Case in Lithuania}

At present Lithuania has a well-developed road network. From this point of view, Lithuania takes a leading position between the East European countries. Lithuanian road network was widely developed till the year 1990. Later, the changes in the road development policy took place with the aim to increase the road pavement quality but not to expand the road network. The length of the road and street network is over 73 $000 \mathrm{~km}$, the length of streets is about $11500 \mathrm{~km}$.

According to their significance Lithuanian roads are divided into roads of national and local significance. The roads of national significance (or state roads) are owned by the Republic of Lithuania, local roads are owned by the municipalities. Based on data of Lithuanian Road Administration the total length of Lithuanian road network of national significance is $21345 \mathrm{~km}$. Roads of national significance are classified as follows: main roads, intended for long-distance freight traffic, that are an integral part of highway connections with neighboring countries; national roads, connecting the centres of territorial administrative units of Lithuania, as well as transit and tourist traffic. The last part of state roads is regional roads. They are used to meet the communication needs of legal or natural persons operating on the territories of territorial administrative units and connecting urban and rural residential locations with the main road network. Table 1 shows the length of roads of national significance in Lithuania. The roads of local significance are dominating in the Lithuanian road network.

Table 1. Length of roads of national significance

\begin{tabular}{|l|c|}
\hline \multicolumn{1}{|c|}{ Road classification } & Length $(\mathrm{km})$ \\
\hline Main roads & 1748 \\
\hline National roads & 4873 \\
\hline Regional roads & 14723 \\
\hline Local roads & about 40000 \\
\hline
\end{tabular}

Though the length of the road network has not been increasing, the number of cars is still growing, at an average $10 \%$ per year. Today the number of cars amounts to 1318000 (see Fig 1).

A dramatic growth of personal travels by car, rail or air from an average of $1820 \mathrm{~km}$ in 1960 to $4390 \mathrm{~km}$ in 1990 [5] causes a number of traffic-related problems in all the capitals and fast-developing countries.

The growing Lithuanian economy and the increasing quality of the living conditions induce population's mobility, the level of car ownership and increasingly high transport flows on the streets and roads of the country $[6,7]$.

Figure 2 shows the state road network in Lithuania in 2006, categorized for the evaluation of accessibility fields to the administrative centres, as well as administrative centres themselves.

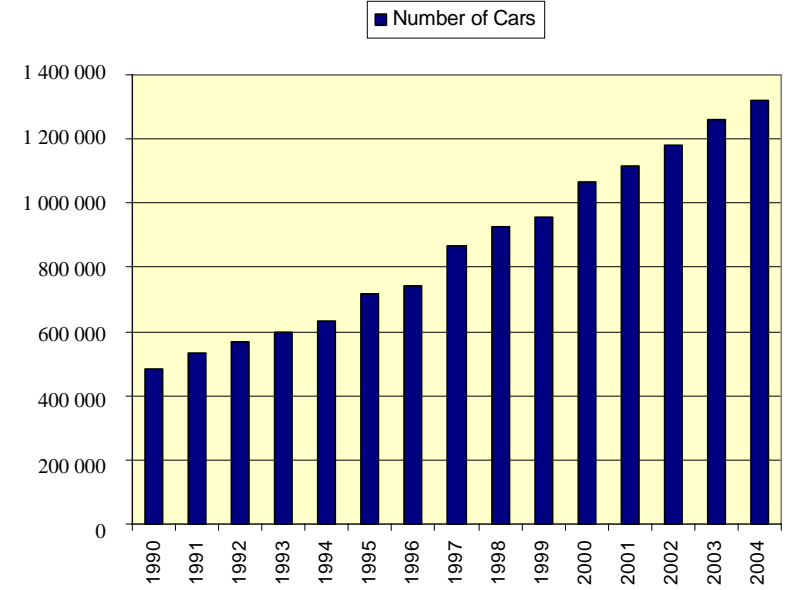

Fig 1. Dynamics in the number of cars

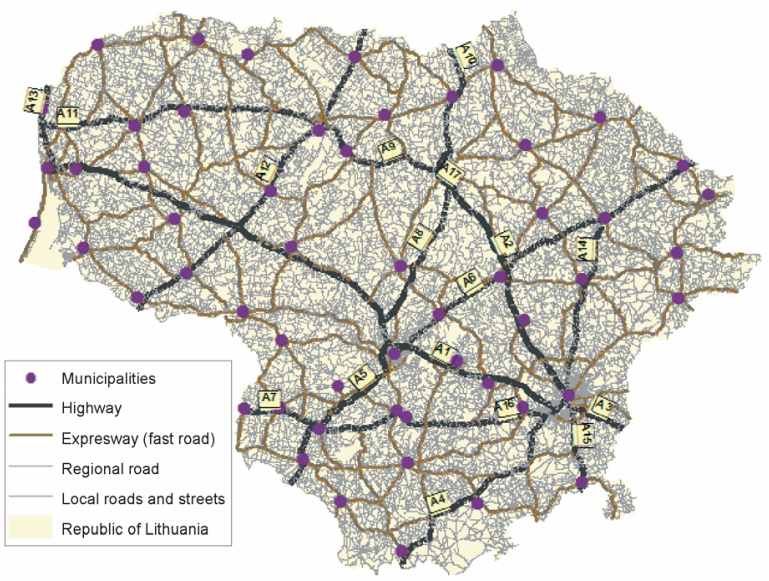

Fig 2. State road network and administrative centres in Lithuania, 2006

GIS model was created, which satisfies the accessibility-based automobile transport system analysis. The input data for GIS application uses a territorial distribution from the regional centre (municipality) and the following statistical data: road network density in regions, density of local roads in regions, length of roads per 1000 inhabitants in administrative regions, length of local roads per 1000 rural inhabitants in administrative regions.

\section{Analysis: algorithms of Lithuanian transport system analysis forecasting potential residential area}

\subsection{Criteria and their importance calculation}

GIS-based decision support system was created, which performs ranking of regions according to their automobile transport system. Table 2 gives the criteria, based on which the automobile transport system ranking was carried out, also the importance of each criterion. The importance was estimated by questioning 28 experts of transportation system [8]. 
Table 2. Importance of criteria

\begin{tabular}{|l|l|l|}
\hline No & \multicolumn{1}{|c|}{ Criteria description } & Function \\
\hline R1 & $\begin{array}{l}\text { Road network density in regions (in each } \\
\text { municipality) }\left[\mathrm{km} / \mathrm{km}^{2}\right]\end{array}$ & maximize \\
\hline R2 & $\begin{array}{l}\text { Density of local roads in regions (in each } \\
\text { municipality) }\left[\mathrm{km} / \mathrm{km}^{2}\right]\end{array}$ & maximize \\
\hline R3 & $\begin{array}{l}\text { Length of roads per 1 000 inhabitants in } \\
\text { administrative regions (municipalities) } \\
{[\mathrm{km}]}\end{array}$ & maximize \\
\hline R4 & $\begin{array}{l}\text { Length of local roads per 1 000 rural in- } \\
\text { habitants in administrative regions (mu- } \\
\text { nicipalities) }[\mathrm{km}]\end{array}$ & maximize \\
\hline R5 & $\begin{array}{l}\text { Percentage coverage of territorial accessi- } \\
\text { bility from the administrative unit going } \\
30 \text { minutes by car from local community } \\
\text { (municipality), } \%\end{array}$ & maximize \\
\hline
\end{tabular}

Table 3 shows the results of experts' questioning. The lowest value means that the criterion is the most important, the highest value means that the criterion is less important $[9,10]$.

Table 3. Results of experts' questioning

\begin{tabular}{|c|c|c|c|c|c|}
\hline $\mathrm{No}$ & 1 & 2 & 3 & 4 & 5 \\
\hline Experts & \multicolumn{5}{|c|}{ Criteria } \\
\hline & R1 & $\mathrm{R} 2$ & R3 & $\mathrm{R} 4$ & R5 \\
\hline E1 & 5 & 4 & 3 & 1 & 2 \\
\hline E2 & 4 & 5 & 1 & 2 & 3 \\
\hline E3 & 5 & 3 & 2 & 1 & 4 \\
\hline E4 & 5 & 4 & 3 & 2 & 1 \\
\hline E5 & 5 & 4 & 2 & 1 & 3 \\
\hline E6 & 5 & 4 & 3 & 1 & 2 \\
\hline E7 & 3 & 4 & 2 & 5 & 1 \\
\hline E8 & 5 & 4 & 3 & 2 & 1 \\
\hline E9 & 4 & 5 & 3 & 1 & 2 \\
\hline E10 & 4 & 5 & 2 & 1 & 3 \\
\hline E11 & 5 & 4 & 3 & 2 & 1 \\
\hline E12 & 5 & 4 & 3 & 2 & 1 \\
\hline E13 & 4 & 5 & 1 & 2 & 3 \\
\hline E14 & 5 & 4 & 3 & 1 & 2 \\
\hline E15 & 5 & 4 & 3 & 2 & 1 \\
\hline E16 & 3 & 2 & 1 & 4 & 5 \\
\hline E17 & 5 & 4 & 3 & 2 & 1 \\
\hline E18 & 5 & 4 & 3 & 2 & 1 \\
\hline E19 & 5 & 2 & 1 & 3 & 4 \\
\hline E20 & 4 & 5 & 3 & 1 & 2 \\
\hline E21 & 5 & 4 & 3 & 2 & 1 \\
\hline E22 & 5 & 4 & 3 & 2 & 1 \\
\hline E23 & 3 & 4 & 2 & 5 & 1 \\
\hline E24 & 5 & 1 & 4 & 3 & 2 \\
\hline E25 & 4 & 5 & 3 & 1 & 2 \\
\hline E26 & 5 & 4 & 3 & 2 & 1 \\
\hline E27 & 5 & 4 & 3 & 2 & 1 \\
\hline E28 & 5 & 4 & 3 & 1 & 2 \\
\hline$t_{\text {sum }}$ & 128 & 110 & 72 & 56 & 54 \\
\hline$t_{\text {avg }}$ & 4.57 & 3.93 & 2.57 & 2.0 & 1.93 \\
\hline
\end{tabular}

1) Calculation of range sum:

$$
t_{\text {sum }, i}=\sum_{j=1}^{l} t_{i j} ;
$$

$i=1,2 . . n, j=1,2 . . l, n=5, l=28 ; t_{\text {sum } 1}=128 ; t_{\text {sum } 2}=$ $110 ; t_{\text {sum } 3}=72 ; t_{\text {sum } 4}=56 ; t_{\text {sum } 5}=54$.

2) Calculation of rang average:

$t_{\text {avg }, i}=t_{\text {sum }, i} / l$;

$t_{\text {avg } 1}=128 / 28=4.57 ; \quad t_{\text {avg } 2}=110 / 28=3.93 ; t_{\text {avg } 3}=$ $72 / 28=2.57 ; t_{\text {avg } 4}=56 / 28=2.00 ; t_{\text {avg } 5}=54 / 28=1,93$.

3) Calculation of subjective criterion's importance:

a) $g_{i}=\frac{t_{\text {avg }, i}}{\sum_{i=1}^{n} t_{\text {avg }, i}}$;

$g_{1}=4.57 / 15=0.305 ; g_{2}=3.93 / 15=0.262 ; g_{3}=2.57 / 15=$ $0.171 ; g_{4}=2.00 / 15=0.133 ; g_{5}=1.93 / 15=0.129$.

b) $q_{i}=1-g_{i}$;

$q_{1}=1-0.305=0.695 ; \underline{q}_{2}=1-0.262=0.738 ; \underline{q}_{3}=1-$ $0.171=0.829 ; \underline{q}_{4}=1-0.133=0.867 ; \underline{q}_{5}=1-0.129=$ 0.871 ;

$$
\begin{aligned}
& \sum_{i=1}^{n} \underline{q}_{i}=0.695+0.738+0.829+0.867+0.871=4 . \\
& \text { c) } q_{i}=\frac{\underline{q}_{i}}{\sum_{i=1}^{n} \underline{q}_{i}}
\end{aligned}
$$

$q_{1}=0.695 / 4=0.174 ; q_{2}=0.738 / 4=0.185 ; q_{3}=0.829 / 4=$ $0.207 ; q_{1}=0.867 / 4=0.217 ; q_{1}=0.871 / 4=0.218$.

4) Calculation of criterion's set of sum-square:

$$
\begin{aligned}
& S=\sum_{i=1}^{n}\left(\sum_{j=1}^{l} t_{i j}-\frac{1}{n} \times \sum_{i=1}^{n} \sum_{j=1}^{l} t_{i j}\right)^{2} ; \\
& \frac{1}{6} \sum_{i=1}^{6} \sum_{j=1} t_{i j}=84 ; \\
& S=\sum_{i=1}^{6}\left(\sum_{j=1}^{28} t_{i j}-84\right)^{2}=(128-84)^{2}+(110-84)^{2}+ \\
& (72-84)^{2}+(56-84)^{2}+(54-84)^{2}=4440 .
\end{aligned}
$$

5) Estimation of concordation coefficient:

$$
W=\frac{12 \times S}{l^{2}\left(n^{3}-n\right)} ;
$$


$W=\frac{12 \times 4440}{28^{2} \times\left(5^{3}-5\right)}=0.566$

6) Estimation of variance:

$v=n-1=5-1=4, \chi_{\mathrm{TABLE}}^{2}=13.277$.

$\chi^{2}=\frac{12 \times S}{l \times n(n+1)} ;$

$\chi^{2}=\frac{12 \times 4440}{28 \times 5(5+1)}=63.429$.

7) Validation results of experts' questioning:

a) $W>0, W=0.566>0$;

b) $\chi^{2}>\chi_{\text {TABLE}}^{2}, 63.429>13.277$.

$\left(\chi_{\mathrm{TABLE}}^{2}=13,277\right.$, when variance is $v=n-1=5-1=$ 4 and significance level $1 \%$ ).

\subsection{Accessibility calculation from administrative centre}

It was estimated that the main criterion, which defines the automobile transportation system, is accessibility from the administrative centre (see Fig 3). Accessibility was calculated by using ArcGIS software.

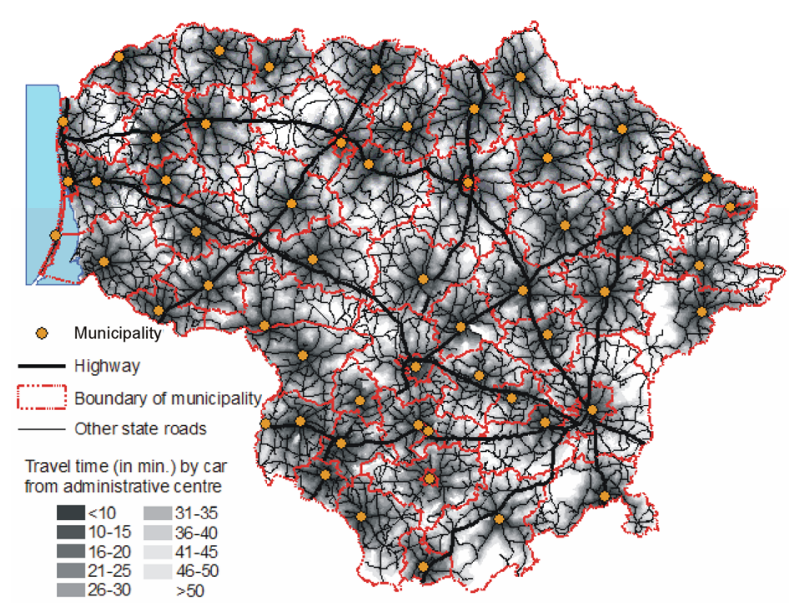

Fig 3. Travel time from administrative centres in Lithuania, 2006

In general, accessibility was calculated under the following conditions:

- taking the time barriers of 5 minutes and the period of one hour;

- travel time was considered to be the optimal criterion;

- in order to make a correct analysis the oneway direction and the possible turns were included into the calculation model.
For the purpose of transport system analysis the percentage coverage of territorial accessibility from the administrative unit traveling 30 minutes by car from local community (municipality) was used.

When calculating ranks, describing the level of automobile transport system in each municipality, the calculation methods such as SAW and TOPSIS [8, 9, 11] were used. GIS-based application computes the ranks of automobile system for the administrative unit. GIS application averages results of the calculations by $S A W$ and TOPSIS.

\subsection{SAW (Simple Additive Weighting) method in GIS application}

A fragment of input regional statistical data for GIS application is shown in Table 4.

Table 4. Fragment of input regional statistical data

\begin{tabular}{|l|c|c|c|c|c|}
\hline & \multicolumn{5}{|c|}{ Criteria } \\
\hline Municipality & $\mathrm{R} 1$ & $\mathrm{R} 2$ & $\mathrm{R} 3$ & $\mathrm{R} 4$ & $\mathrm{R} 5$ \\
\hline Utena & 95.88 & 26.60 & 1.24 & 1.06 & 68 \\
\hline Jonava & 51.01 & 17.64 & 0.98 & 0.95 & 72 \\
\hline Zarasai & 104.8 & 58.19 & 1.01 & 0.96 & 64 \\
\hline Importance (q) & $\mathbf{0 . 1 7 4}$ & $\mathbf{0 . 1 8 5}$ & $\mathbf{0 . 2 0 7}$ & $\mathbf{0 . 2 1 7}$ & $\mathbf{0 . 2 1 8}$ \\
\hline Function & $\max$ & $\mathbf{m a x}$ & $\mathbf{m a x}$ & $\mathbf{m a x}$ & $\mathbf{m a x}$ \\
\hline
\end{tabular}

The input data, used for the calculation, is: criteria and their values of importance;

Criteria matrix is normalized under the following conditions:

If criterion is maximized:

$$
X_{i j}=\frac{X_{i j}}{X_{j}^{\max }} .
$$

If criterion is minimized:

$$
X_{i j}=\frac{X_{j}^{\min }}{X_{i j}} .
$$

Table 5 shows normalized criteria matrix, which was calculated according to formula (9).

Table 5. Normalized criteria matrix for SAW calculation

\begin{tabular}{|l|c|c|c|c|c|}
\hline & \multicolumn{5}{|c|}{ Normalized criteria (SAW) } \\
\hline Municipality & R1 & R2 & R3 & R4 & R5 \\
\hline Utena & 0.91 & 0.46 & 1 & 1 & 0.94 \\
\hline Jonava & 0.49 & 0.30 & 0.79 & 0.90 & 1 \\
\hline Zarasai & 1 & 1 & 0.81 & 0.91 & 0.89 \\
\hline
\end{tabular}

Testing condition of importance:

$\sum q_{i}=1$;

$0.174+0.185+0.207+0.217+0.218=1$.

Municipalities ranking calculation:

Utena $=0.91 \times 0.174+0.46 \times 0.185+1 \times 0.207+$ $1 \times 0.217+0.94 \times 0.218=0.873$;

Jonava $=0.49 \times 0.174+0.30 \times 0.185+0.79 \times$ $0.207+0.90 \times 0.217+1 \times 0.218=0.717$; 
Zarasai $=1 \times 0.174+1 \times 0.185+0.81 \times 0.207+$ $0.91 \times 0.217+0.89 \times 0.218=0.918$

Zarasai $>$ Utena $>$ Jonava.

After the matrix is normalized, each criterion of a concrete municipality is multiplied by its importance. The multiplied criteria are summed for each row (for each municipality). The largest value means the best variant for automobile transport system in the administrative region $[12,13]$.

\subsection{TOPSIS (Technique for Order Preference by Similarity to Ideal Solution) method in GIS application}

1) Criteria matrix is normalized by the formula:

$$
\begin{aligned}
& X_{i j}=\frac{X_{i j}}{\sqrt{\sum_{j=1}^{l} X_{i j}^{2}}} ; \\
& \sqrt{\sum_{j=1}^{l} X_{1 j}^{2}}(\mathrm{R} 1)= \\
& \sqrt{95.88^{2}}+\sqrt{51.01^{2}}+\sqrt{104.80^{2}}=150.92 ; \\
& \sqrt{\sum_{j=1}^{l} X_{2 j}^{2}}(\mathrm{R} 2)= \\
& \sqrt{26.60^{2}}+\sqrt{17.64^{2}}+\sqrt{58.19^{2}}=66.37 ; \\
& \sqrt{\sum_{j=1}^{l} X_{3 j}^{2}}(\mathrm{R} 3)= \\
& \sqrt{1.24^{2}}+\sqrt{0.98^{2}}+\sqrt{1.01^{2}}=1.88 ; \\
& \sqrt{\sum_{j=1}^{l} X_{4 j}^{2}}(\mathrm{R} 4)= \\
& \sqrt{1.06^{2}}+\sqrt{0.95^{2}}+\sqrt{0.96^{2}}=1.72 ; \\
& \sqrt{\sum_{j=1}^{l} X_{5 j}^{2}}(\mathrm{R} 5)= \\
& \sqrt{68^{2}}+\sqrt{72^{2}}+\sqrt{64^{2}}=117.92 ;
\end{aligned}
$$

2) According to formula (12) the normalized criteria matrix is calculated and shown in Table 6.

Table 6. Normalized criteria matrix for TOPSIS calculation

\begin{tabular}{|c|c|c|c|c|c|}
\hline & \multicolumn{5}{|c|}{ Normalized criteria (TOPSIS) } \\
\hline Municipality & R1 & R2 & R3 & R4 & R5 \\
\hline Utena & 0.64 & 0.40 & 0.66 & 0.62 & 0.58 \\
\hline Jonava & 0.34 & 0.27 & 0.52 & 0.55 & 0.61 \\
\hline Zarasai & 0.69 & 0.88 & 0.54 & 0.56 & 0.54 \\
\hline
\end{tabular}

3) Criteria matrix is multiplied by the matrix of importance values [8]:

$$
P^{*}=[X] \times[q] ;
$$

where $q$ - matrix of criterion's importance value.

$$
\begin{gathered}
P^{*}=\left[\begin{array}{lllll}
0.64 & 0.40 & 0.66 & 0.62 & 0.58 \\
0.34 & 0.27 & 0.52 & 0.55 & 0.61 \\
0.69 & 0.88 & 0.54 & 0.56 & 0.54
\end{array}\right] \times \\
{\left[\begin{array}{lllll}
0.174 & 0.185 & 0.207 & 0.217 & 0.218
\end{array}\right]=} \\
{\left[\begin{array}{lllll}
0.111 & 0.074 & 0.137 & 0.134 & 0.126 \\
0.059 & 0.049 & 0.108 & 0.120 & 0.133 \\
0.121 & 0.162 & 0.111 & 0.121 & 0.118
\end{array}\right] .}
\end{gathered}
$$

Normalized matrix is used for calculating an ideal positive $\left(f_{j}^{+}\right)$and negative $\left(f_{j}^{-}\right)$variants.

4) Formation of an ideal positive variant:

If the criterion is minimized, it is necessary to take the minimal value from each row. If the criterion is maximized, we take maximal value from each row (in our case all the criteria are maximized):

$$
f_{j}^{+}=\{0.121 ; 0.162 ; 0.137 ; 0.134 ; 0.133\} .
$$

5) Formation of an ideal negative variant:

If the criterion is minimized, it is necessary to take the maximal value from each row. If the criterion is maximized, we take minimal value from each row (in our case all the criteria are maximized):

$$
f_{j}^{-}=\{0.059 ; 0.049 ; 0.108 ; 0.120 ; 0.118\} \text {. }
$$

6) Calculation of the variant's deviation from an ideal positive variant:

$$
\begin{aligned}
& L_{j}^{+}=\sum_{i=1}^{n}\left(f_{i j}-f_{j}^{+}\right)^{2} ; \\
& L_{\text {Utena }}^{+}=\sqrt{(0.111-0.121)^{2}}+\sqrt{(0.074-0.162)^{2}}+ \\
& \sqrt{(0.137-0.137)^{2}}+\sqrt{(0.134-0.134)^{2}}+ \\
& \sqrt{(0.126-0.133)^{2}}=0.105 \text {; } \\
& L_{\text {Jonava }}^{+}=\sqrt{(0.059-0.121)^{2}}+\sqrt{(0.049-0.162)^{2}}+ \\
& \sqrt{(0.108-0.137)^{2}}+\sqrt{(0.120-0.134)^{2}}+ \\
& \sqrt{(0.133-0.133)^{2}}=0.218 \text {; } \\
& L_{\text {Zarasai }}^{+}=\sqrt{(0.121-0.121)^{2}}+\sqrt{(0.162-0.162)^{2}}+ \\
& \sqrt{(0.111-0.137)^{2}}+\sqrt{(0.121-0.134)^{2}}+ \\
& \sqrt{(0.118-0.133)^{2}}=0.054 \text {. }
\end{aligned}
$$


7) Calculation of the variant's deviation from a negative variant:

$$
\begin{aligned}
& L_{j}^{-}=\sum_{i=1}^{n}\left(f_{i j}-f_{j}^{-}\right)^{2} \text {; } \\
& L_{\text {Utena }}^{-}=\sqrt{(0.111-0.059)^{2}}+\sqrt{(0.074-0.049)^{2}}+ \\
& \sqrt{(0.137-0.108)^{2}}+\sqrt{(0.134-0.120)^{2}}+ \\
& \sqrt{(0.126-0.118)^{2}}=0.133 \text {; } \\
& L_{\text {Jonava }}^{-}=\sqrt{(0.059-0.059)^{2}}+\sqrt{(0.049-0.049)^{2}}+ \\
& \sqrt{(0.108-0.108)^{2}}+\sqrt{(0.120-0.120)^{2}}+ \\
& \sqrt{(0.133-0.118)^{2}}=0.015 \text {; } \\
& L_{\text {Zarasai }}^{-}=\sqrt{(0.121-0.059)^{2}}+\sqrt{(0.162-0.049)^{2}}+ \\
& \sqrt{(0.111-0.108)^{2}}+\sqrt{(0.121-0.120)^{2}}+ \\
& \sqrt{(0.118-0.118)^{2}}=0.179 \text {. }
\end{aligned}
$$

8) Calculation of proportional variant's deviation from an ideal variant $K_{B I T}$ :

$$
\begin{aligned}
& K_{B I T}=\frac{L_{j}^{-}}{L_{j}^{+}+L_{j}^{-}} ; \\
& K_{\text {BIT,Utena }}=\frac{0.133}{0.105+0.133}=0.559 ; \\
& K_{\text {BIT,Jonava }}=\frac{0.015}{0.218+0.015}=0.064 ; \\
& K_{\text {BIT,Zarasai }}=\frac{0.179}{0.054+0.179}=0.768 .
\end{aligned}
$$

The best variant of automobile transportation system in the region is that with the highest $K_{B I T}$ value.

\section{Application and results of the method}

Accessibility-based automobile transport system analysis was carried out for Lithuanian administrative regions. Fig 4 shows the calculation results. The ranking results are calibrated and averaged by using TOPSIS and SAW methods.

Calculation of administrative regions ranking was performed for all Lithuanian local municipalities.

\section{Conclusions}

1. The analysis results showed that the situation of the automobile transport system in central and south eastern part of Lithuania is not as good as in the other Lithuanian parts. In these parts it is necessary to allocate more investments for the development and expansion of the road network.

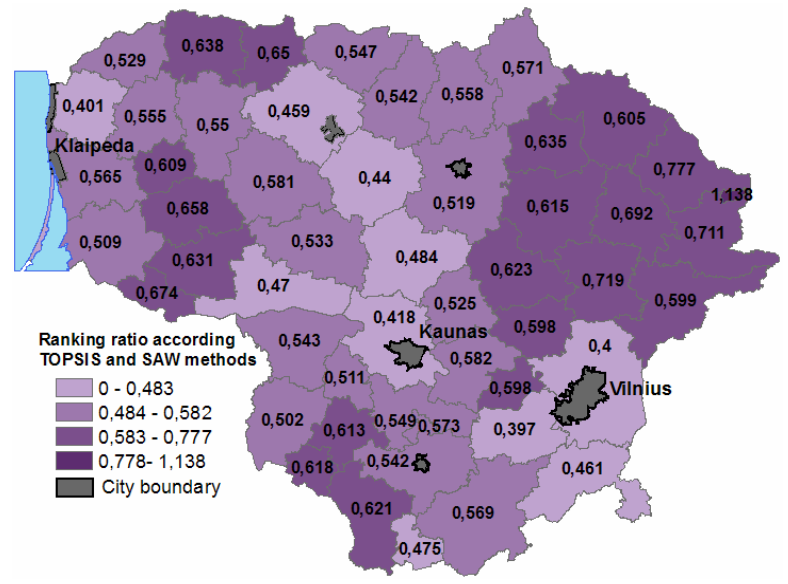

Fig 4. Automobile transport system ranking in Lithuanian regions, 2006

2. The created model could be successfully used for planning administrative boundaries according to the travel time of inhabitants from the administrative centre. A rational planning of administrative boundaries optimizes the travel time for inhabitants.

3. The developed mechanism of automobile transport system analysis, potential residential area forecasting and vector database could be published on the general GIS for public use with the help of attribute information server and ESRI technologies.

4. The developed database structure and calculation mechanism could be easily adapted by the other countries for analysing automobile transport system. It is necessary to supply a database model with the characteristic GIS data.

\section{References}

1. DE JONG, T.; RITSEMAN van ECK, J. R. Location profile-based measures as an improvement on accessibility modelling in GIS. Computers, Environment and Urban Systems, 1997, 20 (3), p. 181-190.

2. DONNAY, J. P.; LEDENT, Ph. Modelling of accessibility fields. In Proceedings JEC-GI '95, I, 1995, p. 489-494.

3. JULIÃO, R. P. Measuring accessibility using GIS. In Geo Computation Proceedings, 1999. Available from Internet: <http://www.geovista.psu.edu/sites/geocomp99/Gc99/010 /gc_010.htm>, data accessed: 20-04-2005.

4. DROBNE, S. Modelling accessibility fields in Slovenian municipalities. In Proceedings of the 7th Symposium on Operation Research in Slovenia (SOR'03), 2003, p. 89-96.

5. SCHAFER, A. The global demand for motorized mobility. Transportation Research, 1998, Vol 32, No 6, p. 455-477.

6. GRIGONIS, V.; BURINSKIENĖ, M. Development scenarios for Vilnius public transport. Urbanistika ir architektūra, 2003, Vol XXVII, Supplement, p. 25-33. 
7. BURINSKIENE, M.; PALIULIS, G. Consistence of car's parking in Lithuanian towns. Transport, 2003, Vol XVIII, No 4, p. 174-181.

8. ZAVADSKAS, E. K.; KAKLAUSKAS, A.; BANAITIENÉ, N. Multiple criteria analysis of a buildings life cycle. Vilnius: Technika, 2001, 380 p. (in Lithuanian).

9. STAN, C. M. GIS and models of accessibility potential: an application in planning. International Journal of Geographical Information Systems, 1995, Vol 9, No 1, p. 67-80.

10. BLACK, J. A.; PAEZ, A.; SUTHANAYA, P. A. Sustainable urban transportation: performance indicators and some analytical approaches. Journal of Urban Planning and Development, 2002, Vol 128, No 4, p. 184-209.

11. ZAVADSKAS, E. K.; SIMANAUSKAS, L.; KAKLAUSKAS, A. Decision support systems in construction: monograph (Sprendimu paramos sistemos statyboje: monografija).Vilnius: Technika, 1999, 235 p. (in Lithuanian).

12. ARAMPATZIS, G.; KIRANOUDIS, C. T.; SCALOUBACAS, P.; ASSIMACOPOULOS, D. A GIS-based decision support system for planning urban transportation policies. European Journal of Operational Research, 2004, 152, p. 465-475.

13. BROWN, A. L. A GIS-based environmental modeling system for transportation planners. Computers, Environment and Urban Systems, 2002, 26, p. 577-590. 